\title{
Design and Development of IoT Integrated PLC Based Material Handling System
}

\author{
Arockia Selvakumar A., Aniket Babar
}

\begin{abstract}
The industry faces with constant demand of tremendous Production criteria to be met with human workers this production rate is highly likely to fall behind as the time progresses, to solve the problem to obtain continuous production without any interruption, this paper helps understand how a manipulator will work for a very basic operations and how will the industry executive will be able to manage the shop floor. This project aims to show how a PLC is used in a automation and how a PLC based system is integrated with a IoT platform
\end{abstract}

Keywords: Failure mode, Force, IoT, Manipulator, PLC, Torque.

\section{INTRODUCTION}

Today's industry needs automation and robotics to be in the competition. Industry has reached a crucial turn and it has revolutionized the processes that are being carried out. As always the primary objective of any industry is, increase productivity with minimum possible investment, safe work environment, increase precision, lower human fatigue, and overall increase efficiency of the industry, like the book "Machine Has changed the world" by the author James P. Womack and before that Japanese Auto-Manufacturer Toyota developed it into lean manufacturing. This method required communication to flow in both directions and increased quality while reducing time and cost, directions of communications are process improvement and error occurring. This has become possible with the help of two engineering aspects which are Industrial Automation and Robotics. If any industry aims to be more efficient, repetitive work should be assigned to the robot or it can be automated and human resources can be reassigned to the work where there is more flexibility required which will increase the productivity and accuracy at the same time. Robotic manipulators can be used as material handling unit or temporary storage for work under progress work pieces which comes under repetitive work sub domain. The material handling systems is built for the sole purpose of education, since there is lack of systems that can aid the students aspiring to become an automation and robotics engineer due to lack of equipment and exposure to the industrial grade practices. This manipulator is part of that project. The material handling unit

Revised Manuscript Received on December 02, 2019

* Correspondence Author

Dr. A. Arockia Selvakumar*, Senior Associate Professor, Design and Automation Research group, School of Mechanical and Building Sciences, Vellore Institute of Technology, Chennai, Tamil Nadu, India.

Email: arockiaselvakumar@yahoo.co.in

Aniket Babar, Senior Associate Professor, Design and Automation Research group, School of Mechanical and Building Sciences, Vellore Institute of Technology, Chennai, Tamil Nadu, India. is a part of a full assembly line industrial grade model which has been developed solely for the purpose of education. The manipulator should be simple enough so that the students can understand the concepts of the manipulator through the application point of view such as determining of the parameters, principle steps were to analyze worksite of present system, formulate and simulate ulterior solutions, and finally analyze the requirement of robotics system [1]. i.e. visualize the application and then determine what constraints are to be put in place. This is done using certain steps After designing of the manipulator the control system that should be implemented should be able to make the manipulator work without imploding [2] PID controllers are not suitable for high speed operation [3] since the computational parameters can be effectively found with computed torque control and feed forward dynamic If the manipulator is designed with a control system that is modeled based on torque level control, precision of the system is increased [4]. Taguchi method based on Stochastic colored Petri nets (SCPN) [5] is one of the effective methods to program a system to be a potential automatic storage and retrieval system (ASRS). Conventional storage unit and ASRS units are vastly different not only on human interface [6] but to organization and inventory management. In order to make Manipulator work as integrated part of ASRS unit is to calculate constraints such as path planning and operation time and we can reduce this using [7]. Traveling Salesmen method. Fragmentation [8] is a fault commonly occurred while running ASRS operation overlapping of the commands or skipping then familiar command is result of the process, concluding that a manipulator working originally with given parameters would not be efficient it handle ASRS tasks. Considering above conclusion reducing the number of parameters to deal with is one of the possibilities to add ASRS tasks to manipulator is that make rules for that will utilize and program the manipulator for small areas only. but it takes considerable amount of time to commission and high maintenance which is not recommended [9]. Plan peak travel times for each terminal cases in order to reduce the operational timing of the ASRS manipulator [10] Model based on the Dwell points such as model based on minimization of expected travel time and minimization of the maximum travel time which will help the designer to calculate the minimum time required to operate [11] In some cases it has been stated that models such as analytical model that will utilize the data of how a given space can be used and path planning the manipulator should function vastly efficient [12]. 


\section{Design and Development of IoT Integrated PLC Based Material Handling System}

When it comes to IoT and exchange of data the most important factor is security of the data and it can be improved by studying the middle-ware of the system [13] As well as if system is supposed to be real time the communication system should be exceptional and data [14] transfer should be more effective such as Constrained Application Protocol (CoAP) and Representational State Transfer (REST) For latest PLC modules that are in the market the communication protocol should be easy less complex and accessible [15] such as PROFIBUS or PROFINET

\section{OBJECTIVE \& SCOPE}

- To develop a system capable of handling the material from pneumatic press to automatic storage and retrieval system (ASRS).

- To integrate the system with IoT

\section{PROPOSED SYSTEM}

The proposed system is a material handling system with following structure that it will follow, fig 1 shows the block diagram representation that shows the components that are needed to design and implement a manipulator similarly in fig 2 what will be the Control and communication system of the system should be is given.

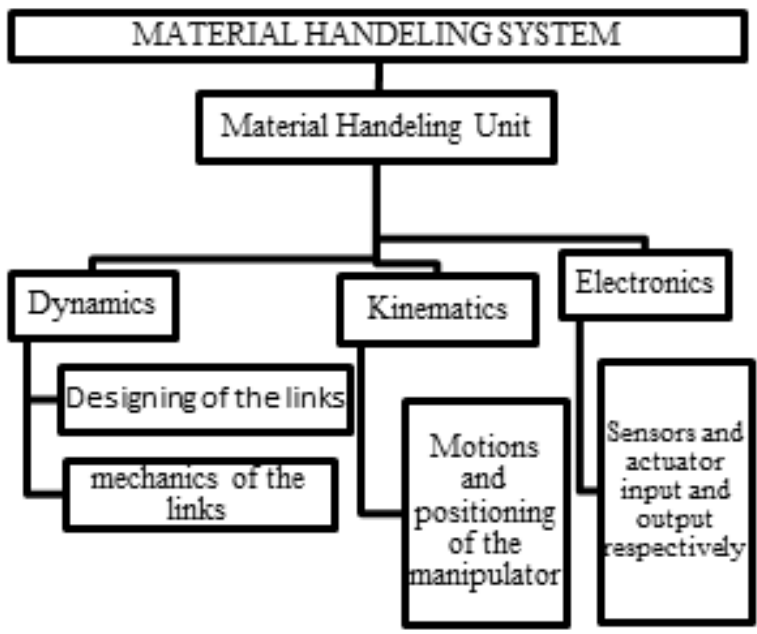

Fig. 1. Block of diagram material handling system

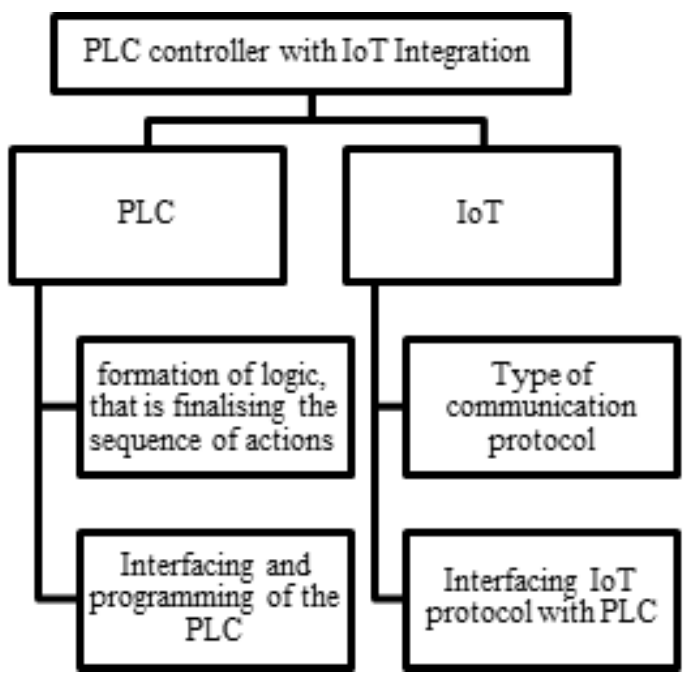

Fig. 2. PLC controller with IoT integration Block diagram fig 3 represents the conceptual design of the manipulator arm that is to be implemented in the system

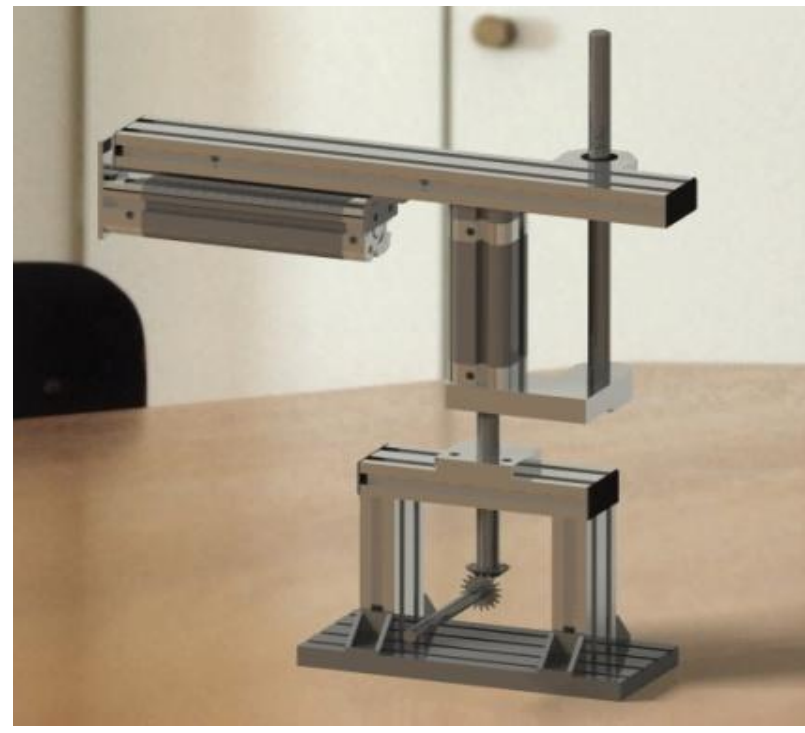

Fig. 3. Concept manipulator arm.

\section{MANIPULATOR}

Manipulator has to work within the given angular constraints which are shown in the format of a block diagram in fig 6 .

\subsection{Manipulator Specifications}

In Robotic manipulator we need configuration, transformation matrix, design of the actuators, placement of the sensors. For the current system we require manipulator with work space shown in fig.4.

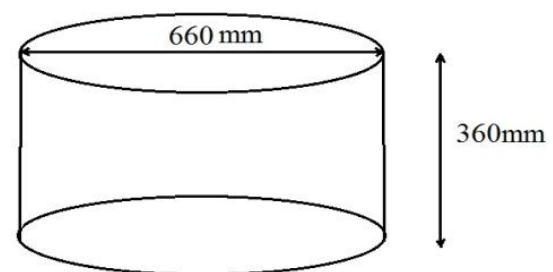

Fig. 4. Manipulator Workspace.

Configuration of the desired manipulator shown in fig 5 the designed structure is shown fig 6 illustrates the joint axis of the desired manipulator which will help in finding out $\mathrm{DH}$ parameters.

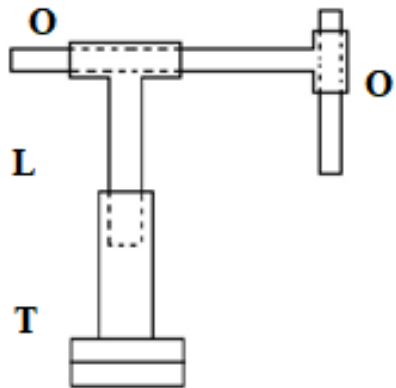

Fig. 5. Manipulator Configuration.

Published By: 


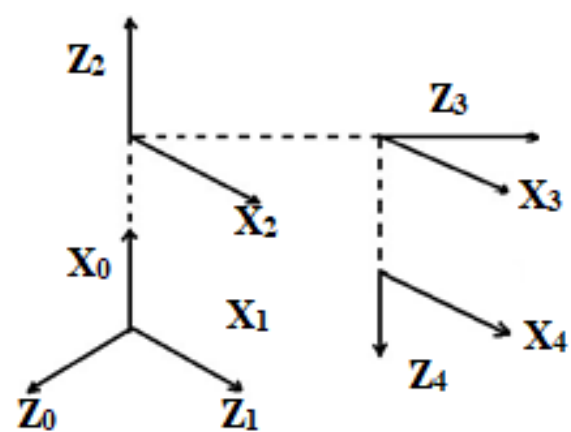

Fig. 6. Joint Axes of manipulator.

4.2. Manipulator DH Parameters

Table I: DH Parameters.

\begin{tabular}{|c|c|c|c|c|}
\hline $\begin{array}{l}\text { Joints } \\
\text { (i) }\end{array}$ & $\begin{array}{c}\text { Twist } \\
\text { angle }(\theta)\end{array}$ & $\begin{array}{c}\text { Offset } \\
\text { along } \\
\text { Z-axis } \\
\text { (d) }\end{array}$ & $\begin{array}{l}\text { Link } \\
\text { length } \\
\text { (a) }\end{array}$ & $\begin{array}{c}\text { Joint } \\
\text { angle } \\
(\alpha)\end{array}$ \\
\hline $0-1$ & $\boldsymbol{\theta}_{0}$ & 0 & 0 & 0 \\
\hline $1-2$ & 0 & $\mathrm{~d}_{1}$ & 0 & 0 \\
\hline $2-3$ & 0 & 0 & $a_{2}$ & $-\pi / 2$ \\
\hline $3-4$ & 0 & 0 & $a_{3}$ & $-\pi / 2$ \\
\hline
\end{tabular}

4.3. Transformation Matrices for individual joints and manipulator

$$
\begin{aligned}
{ }_{0} \mathrm{~T}^{1} & =\left[\begin{array}{cccc}
\cos \theta & -\sin \theta & 0 & 0 \\
\sin \theta & \cos \theta & 0 & 0 \\
0 & 0 & 1 & 0 \\
0 & 0 & 0 & 1
\end{array}\right]{ }_{1} \mathrm{~T}^{2}=\left[\begin{array}{cccc}
1 & 0 & 0 & 0 \\
0 & 1 & 0 & 0 \\
0 & 0 & 1 & d 1 \\
0 & 0 & 0 & 1
\end{array}\right] \\
{ }_{2} \mathrm{~T}^{3} & =\left[\begin{array}{cccc}
1 & 0 & 0 & a 2 \\
0 & 0 & 1 & 0 \\
0 & -1 & 0 & 0 \\
0 & 0 & 0 & 1
\end{array}\right] \\
{ }_{0} \mathrm{~T}^{4} & =\left[\begin{array}{cccc}
\cos \theta & \sin \theta & 0 & a 2+a 3 \\
\sin \theta & -\cos \theta & 0 & 0 \\
0 & 0 & -1 & 0 \\
0 & 0 & 0 & 1
\end{array}\right] \mathrm{T}^{4}=\left[\begin{array}{cccc}
1 & 0 & 0 & a 3 \\
0 & 0 & 1 & 0 \\
0 & -1 & 0 & 0 \\
0 & 0 & 0 & 1
\end{array}\right]
\end{aligned}
$$

4.4. Force and Torque components of the manipulator

To make sure the manipulator system holds the structure at designed loads the analysis of the forces is done using Lagrangian method following are the calculation

Observations and conclusion of the, prerequisite information needed to go forth is

Lagrangian constant $=\mathrm{L}=$ Kinetic Energy - Potential Energy

$$
\begin{aligned}
& \text { Torque component }=\mathrm{T}=\frac{d}{d t} \frac{\partial L}{\partial \theta}-\frac{\partial L}{\partial \theta} \\
& \text { Force component }=\mathrm{F}=\frac{d}{d t} \frac{\partial L}{\partial \varphi}-\frac{\partial L}{\partial r}
\end{aligned}
$$

To find the variables we need to examine each link:

$$
\text { Kinetic energy of base link }=\mathrm{K}_{1}=\frac{1}{2} l_{1} \theta^{2}
$$

Kinetic energy of vertical link $=\mathrm{K}_{2}=\frac{\frac{1}{2}}{2} M_{2} v_{2}^{2}+k_{1}$

$$
\begin{aligned}
& =\mathrm{K}_{3}=\frac{1}{2} I_{a} \theta^{2}+\frac{1}{2} M_{3} v_{D}^{2} \\
& \mathrm{~K}_{3=} \frac{\frac{1}{2}}{I_{\mathrm{a}}} \theta^{2}+\frac{1}{2} M_{\mathrm{a}}\left(\dot{r}^{2}+r^{2} \cdot \theta^{2}\right)
\end{aligned}
$$

Now for finding the Moments of inertia for each of the links, assume a tentative structure of the manipulator as follows:

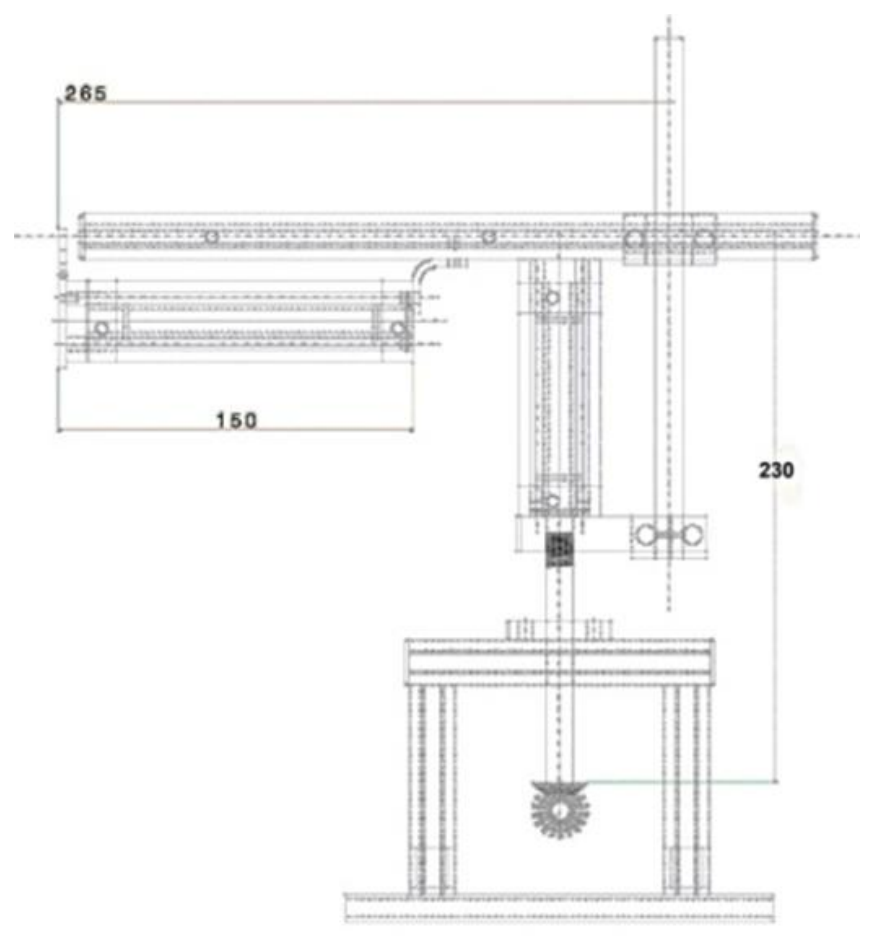

Fig. 7. Desired Manipulator

We will find the moments of inertia for each links.

Moment of inertia is to be found out using the "Theory of Parallel and perpendicular axis for moment of inertia".

Further to calculate Kinetic energy of each link (in terms of $\theta, \theta, \theta, r)$

$$
\begin{aligned}
\mathrm{K}_{1} & =\frac{1}{2} I_{1} \dot{\theta}^{2}=0.9845 \times 10^{-3} \dot{\theta}^{2} \\
\mathrm{~K}_{2}=\frac{1}{2} M_{2} & w_{2}^{2}+k_{1}=\left[1.8792+0.9845 \theta^{2}\right] \times 10^{-3} \\
\mathrm{~K}_{3} & =\frac{1}{2} I_{3} \dot{\theta}^{2}+\frac{1}{2} M_{3}\left(\tilde{r}^{2}+r^{2} \times \dot{\theta}^{2}\right) \\
& =\left[9.5895 \times 10^{-3}+0.493 r^{2}\right] \theta^{2}+0.493 r^{2}
\end{aligned}
$$

Kinetic energy of the system $=\mathrm{K}=\mathrm{K}_{1}+\mathrm{K}_{2}+\mathrm{K}_{3}$

$$
\mathrm{K}=\left\{\left[11.5585 \times 10^{-3}+0.493 r^{2}\right] \theta^{2}+0.493 r^{22}\right\}
$$

For Potential Energy of the system : $\mathrm{P}=\mathrm{P}_{1}+\mathrm{P}_{2}+\mathrm{P}_{3}$ here,

$$
\begin{aligned}
& \mathrm{P}_{1}=\text { P.E. of Link } 1=\frac{\frac{1}{2}}{2} M_{1} g H_{1}=0.10923 \mathrm{~J} \\
& \mathrm{P}_{2}=\text { P.E. of Link } 2=\frac{1}{2} M_{2} g H_{2}=2.385 \mathrm{~J} \\
& \mathrm{P}_{3}=\text { P.E. of Link } 3=\frac{1}{2} M_{a} g H_{a}=2.538 \mathrm{~J} \\
& \mathrm{M}=\text { Mass of respective Link in } \\
& \mathrm{H}=\text { vertical distance of C.G. from datum } \\
& \mathrm{g}=\text { Gravitational acceleration }
\end{aligned}
$$

Thus,

$$
\mathrm{P}=\mathrm{P}_{1}+\mathrm{P}_{2}+\mathrm{P}_{3}=0.10923+2.385+2.538=5.033 \mathrm{~J}
$$




\section{Design and Development of IoT Integrated PLC Based Material Handling System}

According to the Lagrangian constant definition ,

$$
\begin{aligned}
& \mathrm{L}=\text { K.E. - P.E. } \\
& =\left\{\left[11.5585 \times 10^{-3}+0.493 r^{2}\right] \theta^{2}+0.493 r^{2}\right\} \\
& 5.033 \\
& \text { Torque }=\frac{d}{d t} \frac{\partial L}{\partial \theta}-\frac{\partial L}{\partial \theta} \\
& \frac{d}{d t} \frac{\partial L}{\partial \theta}= \\
& {\left[11.5585 \times 10^{-9}+0.493 r^{2}\right] 2 \ddot{\theta}+[0.493 \times 2 \dot{r} \theta]} \\
& \frac{\partial L}{\partial \theta}=0 \\
& \text { Torque }=\frac{d}{d t} \frac{\partial L}{\partial \theta} \\
& =\left[11.5585 \times 10^{-3}+0.493 r^{2}\right] 2 \ddot{\theta}+\left[0.493 \times 2 r^{x} \theta\right] \\
& \text { Force }=\frac{d}{d t} \frac{\partial L}{\partial r}-\frac{\partial L}{\partial r} \\
& \frac{d}{d t} \frac{\partial L}{\partial t}=0.986 \frac{m}{F} \\
& \frac{\partial L}{\partial r}=0.986 r^{*} \\
& \text { Force }=0.986 \ddot{F}-0.986 \tilde{F}^{\tilde{F}}=0.986(\ddot{F}-\dot{F})
\end{aligned}
$$

Torque $=$

$$
\begin{gathered}
{\left[11.5585 \times 10^{-3}+0.493 r^{2}\right] 2 \ddot{\theta}+\left[0.493 \times 2 r^{x} \theta\right]} \\
\text { Force }=0.986 r^{*}
\end{gathered}
$$

Link 1 = base link : M.I. along rotational axis (z-axis) $=$

$$
\mathrm{I}_{1}=1.969 \times 10^{-3} \mathrm{~kg} \cdot \mathrm{m}^{2}
$$

Link 2 = vertical link : M.I, along rotational axis =

$$
\mathrm{I}_{2}=1.4486 \times 10^{-3} \mathrm{~kg} \cdot \mathrm{m}^{2}
$$

Link 3 = Horizontal link : M.I, along rotational axis =

$$
\mathrm{I}_{3}=0.019179 \mathrm{~kg} \cdot \mathrm{m}^{2}
$$

Constraints are provided as follows :

$$
\begin{gathered}
r=\left(160 \times 10^{-3}\right) \mathrm{m} \\
\dot{r}^{*}=0.066 \mathrm{~m} / \mathrm{s} \\
\theta=0.9 \mathrm{rad} / \mathrm{sec} \\
\theta=6 \times 10^{-3} \mathrm{rad} / \mathrm{s}^{2}
\end{gathered}
$$

Thus giving us following constant Torque and force requirement

Theoretical Torque $=\mathrm{T}_{\mathrm{Th}}=16.9322 \mathrm{mNm}$

Required Torque $=\mathrm{T}_{\mathrm{Th}} \times$ Factor of safety

$$
\begin{aligned}
=16.9322 \times 1.2=20.7 \mathrm{mNm} \\
\text { Force }=44.4 \mathrm{mN} \\
\text { Torque }=20.7 \mathrm{mNm} \\
\text { Force }=44.4 \mathrm{mN}
\end{aligned}
$$

\subsection{Motor Selection}

Following parameters are required to select a motor

Load Torque $\left(\mathrm{T}_{\mathrm{L}}\right)=\mathrm{F} \times$ (bevel gear radius)

Acceleration Torque $\left(\mathrm{T}_{\mathrm{a}}\right)$

$$
\mathrm{T}_{\mathrm{L}}=0.44 \mathrm{mNm}
$$

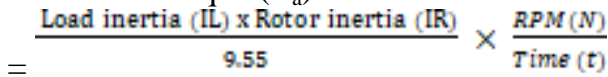

$$
\begin{aligned}
& \mathrm{T}_{\mathrm{a}}=2.4513 \times 10-3 \mathrm{mNm}
\end{aligned}
$$

Required torque $\left(\mathrm{T}_{\mathrm{M}}\right)=$ Load Torque $\left(\mathrm{T}_{\mathrm{L}}\right)+$ Acceleration Torque $\left(\mathrm{T}_{\mathrm{a}}\right)$

Required torque $(\mathrm{TM})=(0.44+2.4513 \times 10-3) \times 1.4$

$$
\mathrm{T}_{\mathrm{M}}=65.6 \mathrm{mNm}
$$

Calculation conclusion $=>$

$$
\begin{gathered}
\text { Stall Torque }=20 \mathrm{mNm} \pm 2 \mathrm{mNm} \\
\text { Operational Torque }=65.6 \mathrm{mNm} \pm 5 \mathrm{mNm}
\end{gathered}
$$

\subsection{Inputs and Outputs of the Manipulator}

The manipulator ladder logic works in 3 different sets which are as follows:

- Define function Blocks

- Pick and place of child parts from conveyor to the Pneumatic press

- Pick and place of finished assembly from pneumatic press to the ASRS platform

First following table is of the memory bits that are used in the program.

Table II: DH Parameters

\begin{tabular}{|r|c|c|}
\hline S.No. & $\begin{array}{c}\text { Memory } \\
\text { bit }\end{array}$ & Function \\
\hline 1 & M1 & Clockwise rotation memory \\
\hline 2 & M2 & $\begin{array}{c}\text { Counter clockwise rotation } \\
\text { memory }\end{array}$ \\
\hline 3 & M3 & Suction cup ON memory bit \\
\hline 4 & M4 & Encoder reading for angle $13^{0}$ \\
\hline 5 & M5 & Encoder reading for angle $90.6^{0}$ \\
\hline 6 & M6 & Encoder reading for angle $104.3^{0}$ \\
\hline 7 & M7 & Encoder reading for angle $280.6^{0}$ \\
\hline 8 & M8 & Encoder reading for angle $193^{0}$ \\
\hline 9 & M9 & $\begin{array}{c}\text { Memory for completion of the } \\
\text { press operation }\end{array}$ \\
\hline
\end{tabular}

In order to understand how a PLC Ladder logic has to be drawn first there is a need of step by step bifurcation of the actions that are carried out by the manipulator system. these actions are classified in 2 different types

- Pick and place from Conveyor to Pneumatic press

- Pick and placed from pneumatic press to ASRS platform

Now that actions are separated and placed in orderly manner it will be easy to carry out building ladder logic.

Thus in the from Figure11 to Figure 26 (Appendix 1) PLC ladder logic of these three set of actions has been shown.

\section{CONCLUSION}

Designed manipulator works with 4 positions namely, Home, Conveyor station, Pneumatic Press station, ASRS platform. The manipulator works with payload of $250 \mathrm{gm}$ with the body weight of $1.2 \mathrm{Kg}$ without compressed air. The manipulator successfully works with 4 bar pressure and has maximum capacity to handle 6 bar air pressure. In order to vary the operation speed regulators such as potentiometer for twisting motor and throttle valves for linear links can vary the operation speed from 10 s/cycle to 30s/cycle. Communication also known as handshake between two PLC in the system has been successfully established. Motor with torque of $65.6 \mathrm{mNm}$ with operational tolerance of $5 \mathrm{mNm}$ refer equation (18). 


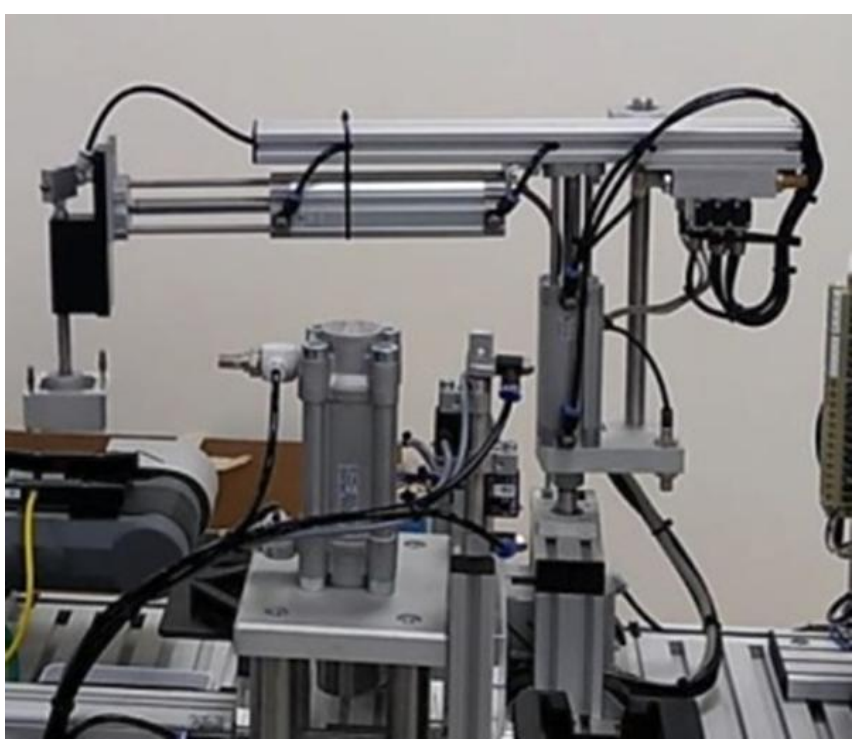

Fig. 8. Actual Manipulator.

\section{APPENDIX}

Table III. Part list

\begin{tabular}{|c|c|c|c|}
\hline S.No. & Part Name & Part Description & Qty \\
\hline 1 & $\begin{array}{l}\text { Pneumatic } \\
\text { Cylinder }\end{array}$ & $\begin{array}{c}\mathrm{R}=10 \mathrm{~mm} \\
\mathrm{~s}=60 \mathrm{~mm}\end{array}$ & 1 \\
\hline 2 & $\begin{array}{l}\text { Pneumatic } \\
\text { Cylinder }\end{array}$ & $\begin{array}{l}\mathrm{R}=10 \mathrm{~mm} \\
\mathrm{~s}=100 \mathrm{~mm}\end{array}$ & 1 \\
\hline 3 & Solenoids & $\begin{array}{c}\text { Used to actuate the } \\
\text { direction control valves }\end{array}$ & 5 \\
\hline 4 & $\begin{array}{l}\text { Vacuum } \\
\text { Ejector }\end{array}$ & $\begin{array}{l}\text { Generates vacuum used to } \\
\text { pick or place the work } \\
\text { piece }\end{array}$ & 1 \\
\hline 5 & Suction Cup & $\mathrm{D}=12 \mathrm{~mm}$ & \\
\hline 6 & DC motor & $\begin{array}{l}\text { Twisting action of the } \\
\text { manipulator is carried out } \\
\text { by DC motor }\end{array}$ & 1 \\
\hline 7 & $\begin{array}{l}\text { Inductive } \\
\text { proximity } \\
\text { Sensor } \\
\end{array}$ & $\begin{array}{c}\text { Helps to calibrate } \\
\text { manipulator at its home } \\
\text { position }\end{array}$ & 1 \\
\hline 8 & $\begin{array}{l}\text { Magnetic } \\
\text { Sensors }\end{array}$ & $\begin{array}{l}\text { Placed at the end of } \\
\text { cylinders to indicate } \\
\text { successful } \\
\text { extension/retraction }\end{array}$ & 4 \\
\hline 9 & Bevel gears & $\begin{array}{l}\text { Used to transmit power } \\
\text { from motor to manipulator }\end{array}$ & 2 \\
\hline 10 & $\begin{array}{l}\text { Planetary } \\
\text { Gear } \\
\text { assembly }\end{array}$ & $\begin{array}{l}1: 120 \text { reduction ratio } \\
(22 \mathrm{E})\end{array}$ & 1 \\
\hline 11 & $\begin{array}{c}5 / 2 \\
\text { direction } \\
\text { control } \\
\text { valves } \\
\end{array}$ & $\begin{array}{l}\text { Used for direction control } \\
\text { of vertical and horizontal } \\
\text { movement in manipulator }\end{array}$ & 2 \\
\hline 12 & $\begin{array}{l}3 / 2 \mathrm{NC} \\
\mathrm{DCV}\end{array}$ & $\begin{array}{l}\text { Used to turn on/off suction } \\
\text { cup control }\end{array}$ & 1 \\
\hline
\end{tabular}

Table IV. PLC I/O and Function

\begin{tabular}{|c|c|c|c|}
\hline S. No. & Inputs & Function & $\begin{array}{c}\text { Outputs } \\
\text { (w.r.t. Inputs) } \\
\end{array}$ \\
\hline 1 & $\begin{array}{l}\text { Encoder } \\
\quad(\text { En })\end{array}$ & $\begin{array}{l}\text { Measures pulses to } \\
\text { determine angles for } \\
\text { precise motor rotation }\end{array}$ & Motor \\
\hline 2 & $\begin{array}{l}\text { Inductive } \\
\text { proximity } \\
\text { sensor } \\
\text { (IP1) }\end{array}$ & $\begin{array}{l}\text { Calibrates manipulator } \\
\text { to be at home position }\end{array}$ & Motor \\
\hline 3 & $\begin{array}{l}\text { Magnetic } \\
\text { sensor } 1 \\
(\mathrm{MS} 1) \\
\end{array}$ & $\begin{array}{l}\text { Senses when vertical } \\
\text { cylinder is in retracted } \\
\text { position }\end{array}$ & $\begin{array}{c}\text { Vertical } \\
\text { cylinder } \\
\text { (cylinder 1) }\end{array}$ \\
\hline 4 & $\begin{array}{l}\text { Magnetic } \\
\text { sensor } 2 \\
(\mathrm{MS} 2) \\
\end{array}$ & $\begin{array}{l}\text { Senses when vertical } \\
\text { cylinder is in extended } \\
\text { position }\end{array}$ & $\begin{array}{c}\text { Vertical } \\
\text { cylinder } \\
\text { (cylinder 1) }\end{array}$ \\
\hline 5 & $\begin{array}{l}\text { Solenoid } 1 \\
\quad(\text { Sol1 })\end{array}$ & $\begin{array}{l}\text { Actuates } 5 / 2 \text { DCV to } \\
\text { actuate vertical cylinder } \\
\text { into extended position }\end{array}$ & $\begin{array}{c}\text { Vertical } \\
\text { cylinder } \\
\text { (cylinder 1) }\end{array}$ \\
\hline 6 & $\begin{array}{l}\text { Solenoid } 2 \\
\quad(\text { Sol2) }\end{array}$ & $\begin{array}{l}\text { Actuates } 5 / 2 \mathrm{DCV} \text { to } \\
\text { actuate vertical cylinder } \\
\text { into retracted position }\end{array}$ & $\begin{array}{c}\text { Vertical } \\
\text { cylinder } \\
\text { (cylinder 1) }\end{array}$ \\
\hline 7 & $\begin{array}{l}\text { Magnetic } \\
\text { sensor } 3 \\
(\mathrm{MS} 3) \\
\end{array}$ & $\begin{array}{l}\text { Senses when horizontal } \\
\text { cylinder is in retracted } \\
\text { position }\end{array}$ & $\begin{array}{l}\text { horizontal } \\
\text { cylinder } \\
\text { (cylinder } 1 \text { ) }\end{array}$ \\
\hline 8 & $\begin{array}{l}\text { Magnetic } \\
\text { sensor } 4 \\
(\mathrm{MS} 4) \\
\end{array}$ & $\begin{array}{l}\text { Senses when horizontal } \\
\text { cylinder is in extended } \\
\text { position }\end{array}$ & $\begin{array}{c}\text { horizontal } \\
\text { cylinder } \\
\text { (cylinder 1) }\end{array}$ \\
\hline 9 & $\begin{array}{l}\text { Solenoid } 3 \\
\quad(\text { Sol3) }\end{array}$ & $\begin{array}{l}\text { Actuates } 5 / 2 \text { DCV to } \\
\text { actuate horizontal } \\
\text { cylinder into extended } \\
\text { position }\end{array}$ & $\begin{array}{l}\text { horizontal } \\
\text { cylinder } \\
\text { (cylinder 1) }\end{array}$ \\
\hline 10 & $\begin{array}{l}\text { Solenoid } 4 \\
\quad(\text { Sol4) }\end{array}$ & $\begin{array}{c}\text { Actuates } 5 / 2 \mathrm{DCV} \text { to } \\
\text { actuate horizontal } \\
\text { cylinder into retracted } \\
\text { position }\end{array}$ & $\begin{array}{l}\text { horizontal } \\
\text { cylinder } \\
\text { (cylinder 1) }\end{array}$ \\
\hline 11 & $\begin{array}{c}\text { Solenoid } 5 \\
(\text { Sol5) }\end{array}$ & $\begin{array}{l}\text { Actuates } 3 / 2 \mathrm{DCV} \text { to } \\
\text { turn suction } \mathrm{ON} \text { or OFF }\end{array}$ & $\begin{array}{l}\text { Vacuum } \\
\text { ejector }\end{array}$ \\
\hline 12 & $\begin{array}{l}\text { Conveyor } \\
\text { End } \\
\text { sensor } \\
\text { (Optical } \\
\text { sensor) }\end{array}$ & Initiates the cycle & Motor \\
\hline
\end{tabular}

\section{REFERENCES}

1. R D Schraft and M C Wanner (1985) "Determination of Important Design Parameters for Industrial Robots from the Application Point of View Survey Paper ", RoManSy and contributors

2. M. C., Sweet, L. M., \& Strobe). K. L. (1985). Dynamic Models for Control System Design of Integrated Robot and Drive Systems. Journal of Dynamic Systems, Measurement, an< Control, 107(1), 53.

3. Jan Swevers, Walter Verdonck, and Joris De Schutte Dynamic Model Identification for Industrial Robots (2007), IEEE, 17(5), 58-71

4. Mikell P. Groover, Automations Production systems and computer aided manufacturing

5. Jingfu Jin, Nicholas Gans Parameter identification for industrial robots with a fast and robust trajectory design approach Robotics and Computer-Integrated Manufacturing 31(2015)21-29

6. A. K. Chincholkar and O. V. Krishnaiah Chetty Simultaneous optimisation of control factors in automated storage and retrieval systems and FMS using stochastic coloured Petri nets and the Taguchi method. Int $\mathrm{J}$ 


\section{Design and Development of IoT Integrated PLC Based Material Handling System}

Adv Manuf Technol (1996) 12:137-144

7. J. Ashayeri, L. Gelders, L. Van Wassenhove :A microcomputer-based optimization model for the Storage system International Journal of Production Research, 23:4, 825-839.

8. E. A. ELSAYED (1981): Algorithms for optimal material handling in automatic warehousing systems, International Journal of Production Research, 19:5, 525-535

9. Henri Tokola, Esko Niemi (2015) : Avoiding Fragmentation in Miniload Automated Storage and Retrieval Systems IFAC-PapersOnLine 48-3 (2015) 1973-1977

10. Ramchandran Jaikumar \& Marius M. Solomon (1990) Dynamic Operational Policies in an Automated Warehouse, IIE Transactions, 22:4, 370-376

11. Pius J. Egbelu (1991) Framework for dynamic positioning of storage/retrieval machines in an automated storage/retrieval system, International Journal of Production Research, 29:1, 17-37

12. F. Eldemir, R. J. Graves \& C. J. Malmborg (2004) New cycle time and space estimation models for automated storage and retrieval system conceptualization, International Journal of Production Research, 42:22, 4767-4783

13. Bidyut Mukherjee, Songjie Wang, Wenyi Lu, Roshan Lal Neupane, Daniel Dunn, Yijie Ren, Qi Su, Prasad Calyam (2018). Flexible IoT security middleware for end-to-end cloud-fog communication, Future Generation Computer Systems Volume 87, October 2018, Pages 688-703

14. A.E. Khaled, S. Helal, Interoperable communication framework for bridging RESTful and topic-based communication in IoT, Future Generation Computer Systems (2018).

15. Matteo Cristani, Florenc Demrozi, Claudio Tomazzoli (2018), An Ontology - Driven methodology for converting PLC industrial Plants into IoT, Procedia Computer Science 126 (2018) 527-536

\section{AUTHORS PROFILE}

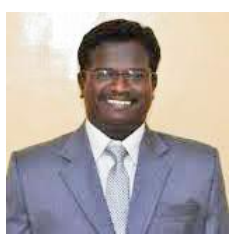

Dr. Arockia Selvakumar A, is member of Design and Automation Research group at the Vellore Institute of Technology, Chennai where he is working as a Senior Associate Professor of School of Mechanical and Building Sciences. He holds a lifetime membership of RSI and a member of IEEE. His field of interest includes Robotics and Automation, IOT, Bio-Mechanics and Finite Element analysis.

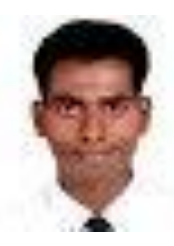

Mr. Aniket Babar, Systems Developer, Robotics and Automation Pvt.Ltd, Pune. He has completed Masters in Mechatronics in Vellore institute of Technology, Chennai in the year 2019. His field of interest includes Robotics and Automation, IOT, Mechatronics Systems. 